\title{
Publicações sobre políticas culturais na Universidade Federal da Bahia: explorações bibliométricas
}

DOI: https://doi.org/10.22409/pragmatizes.v10i19.42693

\author{
Renata Rocha ${ }^{1}$ \\ Leonardo Costa ${ }^{2}$ \\ Nayanna Mattos ${ }^{3}$ \\ Gustavo Brandão ${ }^{4}$
}

Resumo: Este trabalho consiste na apresentação da primeira etapa de levantamento e análise de parte da produção científica - artigos em periódicos, capítulos de livros, dissertações e teses centrada no tema das políticas culturais, realizada na Universidade Federal da Bahia (UFBA), entre os anos de 2005 e 2018. Para tanto, utilizamos a bibliometria como ferramenta para mensurar a produção e disseminação do conhecimento científico a partir das publicações especificadas. A análise se apoia, ademais, em uma discussão contextual e crítica dos dados obtidos. Para a realização da coleta, consideramos como elemento de localização a autoindexação pelo(a) autor(a) nas palavras-chave e a busca do termo "políticas culturais"- e suas múltiplas variantes - nos resumos ou títulos dos diferentes trabalhos. Embora analisados como um conjunto que pode ilustrar o campo dos estudos em políticas culturais na Bahia, os dados são apresentados separados por tipologia da publicação e, devido às suas especificidades, eles não podem ser comparados entre si.

Palavras-chave: Bibliometria; Produção científica; Bahia.

\section{Publicaciones sobre políticas culturales en la Universidad Federal de Bahía: exploaciones bibliométricas}

Resumen: Este artículo presenta una recopilación y un análisis preliminar de parte de la producción científica - artículos en revistas, capítulos de libros, disertaciones de maestría y tesis doctorales centrados en el tema de políticas culturales, realizado en la Universidad Federal de Bahía (UFBA), entre los años 2005 y 2018. Para este fin, utilizamos la bibliometría como herramienta para medir la producción y difusión del conocimiento científico de las publicaciones específicas. El análisis está

\footnotetext{
${ }^{1}$ Renata Rocha (Renata de Paula Trindade Rocha de Souza). Doutora em Cultura e Sociedade pela UFBA, professora da Faculdade de Comunicação da Universidade Federal da Bahia/UFBA, Brasil. Email: renatatrocha@ufba.br - https://orcid.org/0000-0001-9968-012X

${ }^{2}$ Leonardo Figueiredo Costa. Doutor em Cultura e Sociedade pela UFBA, professor da Faculdade de Comunicação da Universidade Federal da Bahia/UFBA, Brasil. E-mail: leocosta@ufba.br https://orcid.org/0000-0001-6095-2642

${ }^{3}$ Nayanna de Mattos Kuchenbecker, graduanda em Produção em Comunicação e Cultura pela Universidade Federal da Bahia, Brasil. Email: mattos.nayanna@gmail.com

${ }^{4}$ Gustavo de Oliveira Brandão, graduando em Produção em Comunicação e Cultura pela Universidade Federal da Bahia. Email:gustavodeoliveirabrandao@gmail.com
} 
respaldado por una discusión contextual y crítica de los datos obtenidos. Para la recopilación,consideramos la auto indexación en palabras clave y la búsqueda del término políticas culturales - y sus múltiples variantes - en el resumen o título de las diferentes obras. Aunque se analizan como un conjunto que puede ilustrar el campo de estudios en políticas culturales en Bahía, los datos se presentan separados por tipo de publicación y, debido a sus especificidades, no pueden compararse entre sí.

Palabras clave: Bibliometría; Producción científica; Bahía.

\section{Cultural policies publications at Federal University of Bahia: a bibliometric exploration}

Abstract: This paper consists in the presentation of a preliminary data collection and analysis of part of the scientific production - articles in journals, book chapters, dissertations and theses - focused on the theme of cultural policies, carried out at Federal University of Bahia (UFBA), between the years of 2005 and 2018. Therefore, we use bibliometrics as a tool to measure the production and dissemination of scientific knowledge from the specified publications. The analysis is supported by a contextual and critical analysis of the obtained data. For the data collection, we considered the author's self-indexing in the keywords and the search for the term cultural policies - and its multiple variants - in the abstract or title of the different works. Although analyzed as a set that can illustrate the field of studies in cultural policies in Bahia, the data are presented separated by type of publication, due to their specificities they cannot be compared with each other.

Keywords: Bibliometrics; Scientific production; Bahia.

Publicações sobre políticas culturais na Universidade Federal da Bahia: explorações bibliométricas

\section{Publicações sobre políticas culturais $^{5}$}

\section{Pressupostos teóricos e demarcações contextuais}

Estudos centrados nas políticas culturais têm se tornando mais presentes ao longo dos últimos anos,

\footnotetext{
${ }^{5}$ Esta é uma versão revista e ampliada do texto "Levantamento de publicações sobre políticas culturais na Universidade Federal da Bahia entre os anos de 2005 e 2018", apresentado e publicado nos anais do XV Encontro de Estudos Multidisciplinares em Cultura (Enecult), realizado em Salvador, Bahia, em agosto de 2019.
}

no Brasil, em instituições e organismos que se dedicam à pesquisa e à formação acadêmica nos diversos níveis. Nesse sentido, a análise do modo como é produzido o conhecimento sobre o tema, além de representar uma tarefa de suma importância para compreender o desenvolvimento desse campo, é alvo de um esforço crescente de pesquisadores (SANTOS, 2017; CALABRE, 2014; BARBALHO; HOLANDA, 2014). 


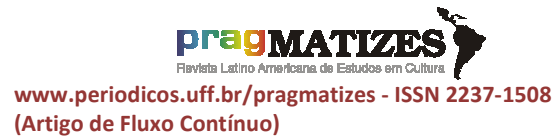

Ainda que de modo breve, fazse necessário explicitar alguns pressupostos teórico conceituais acerca do nosso objeto de pesquisa, uma vez que a conformação dessa área de estudos é marcada por dissensos e dificuldades de conceituação. Inicialmente, optamos por um conceito ampliado de cultura que ultrapasse as artes e o patrimônio - tornando possível a inclusão, no âmbito das políticas culturais, de temas como a diversidade, as culturas populares, a comunicação etc. (ROCHA, 2016). Também partimos do pressuposto de que a noção de políticas culturais extrapola a relação Estado e cultura, visto que outros agentes podem promover políticas para a cultura, a exemplo de instituições privadas, movimentos sociais, grupos e organizações (GARCÍA CANCLINI, 2019).

A conformação desse campo de estudos é resultado de um olhar singular acerca de intervenções práticas, muitas vezes a partir de uma formação teórica oriunda de campos diversificados do conhecimento. Sobretudo a partir do século XXI, a política cultural é investigada nas áreas de sociologia, antropologia, história, arquitetura e nos diversos campos de formação das artes, como no teatro, nas artes visuais e na dança (CALABRE, 2014, p. 111).

Para Alexandre Barbalho (2005, p. 35),

os significados e as lógicas sociais que guiam, ou pretendem guiar, uma determinada política cultural podem sim e devem ser objeto de pesquisas e reflexões científicas segundo 0 local de onde se observa (um olhar histórico, ou antropológico, ou sociológico...). Ou na confluência de áreas que, diga-se de passagem, é o olhar privilegiado, para não dizer mais adequado, para esse tipo de estudo, já que o objeto transcende as delimitações acadêmicas tradicionais. Mas, acima de tudo, tal objeto não está inserido em um saber específico, uma ciência exclusiva denominada 'política cultural'.

Desse modo, a pulverização disciplinar, ainda que benéfica quanto a diversos aspectos, representa um obstáculo na adoção de sentidos, conceitos e terminologias comuns, tão caros ao desenvolvimento teórico e reconhecimento de um domínio científico. Quanto às políticas culturais, como afirma Ana Maria Ochoa Gautier (2003, p. 65-66) a dispersão de sentidos é característica intrínseca ao próprio campo na atualidade.

Ao longo da trajetória dessa área de estudos, é possível identificar o expressivo aumento do número de 
publicações a partir dos anos 2000, em consonância com o que acontecia também no campo das políticas públicas para a cultura no Brasil (CALABRE, 2014). Os primeiros anos do segundo milênio possuem como marca as gestões de Gilberto Gil (2003-2008) e Juca Ferreira (20082011) no Ministério da Cultura, que reestruturaram e ampliaram de forma considerável a atuação do órgão. Foram criados diversos programas e projetos inauguradores, a exemplo do Cultura Viva, DocTV, Revelando os Brasis, entre outros; o conceito de cultura foi ampliado e, consequentemente, o público alvo do órgão; a participação da sociedade civil em suas políticas foi ampliada, entre outras iniciativas.

Para além do aumento das pesquisas e das políticas públicas de cultura, esse momento se caracteriza também pela criação e ampliação de espaços dedicados aos estudos e pesquisas desenvolvidos na área. Instituições, grupos e linhas de pesquisa vinculadas ao tema são criados. Em 2000 surge, no Rio de Janeiro, o setor de pesquisas em Políticas Culturais da Fundação Casa de Rui Barbosa, então chefiado por Lia
Calabre. Em Minas Gerais, no ano de 2005, inicia-se a atuação do Observatório da Diversidade Cultural, coordenado por José Márcio Barros e José Oliveira Júnior, então ligado à Pontifícia Universidade Católica de Minas (PUC-MG). Dois anos depois, nasce na Bahia a Rede de Pesquisadores em Políticas culturais (Redepcult), que, embora não seja constituída formalmente, reúne renomados pesquisadores de diversos estados da Federação, com 0 desenvolvimento de iniciativas conjuntas.

Esse contexto pujante também influencia a Bahia. Cabe observar, porém, que o poder público estadual, desde a década de 1990, já vinha sendo alvo de uma série de reflexões, motivadas por sua forte relação com a cultura e identidade baianas, enquanto estratégia para a promoção do turismo e legitimação política, em sucessivas gestões de políticos vinculados a Antonio Carlos Magalhães. As relações entre cultura e Estado se modificam e adquirem novos contornos apenas no ano de 2007, com a eleição de Jaques Wagner para governador, resultando na desvinculação entre a cultura e o 
turismo; e na escolha de Márcio Meirelles para gerir a recém-criada Secretaria de Cultura.

O estado adquire singular relevância para o estudo das políticas culturais, demonstrada em pesquisas como a de Marcelo Augusto de Paiva Santos (2017) e Lia Calabre (2014), por meio da profícua atuação de dois órgãos que se dedicaram especialmente a esse campo de reflexão, ambos vinculados à Universidade Federal da Bahia (UFBA): 0 Centro de Estudos Multidisciplinares em Cultura (CULT) e o Programa Multidisciplinar de PósGraduação em Cultura e Sociedade (Pós-Cultura).

O CULT, criado em 2003, é um órgão complementar da UFBA que possui, desde 0 início de suas atividades, uma linha de pesquisa em políticas culturais. Dentre outras relevantes iniciativas para a consolidação dessa temática, envolvendo pesquisa, ensino e extensão, o CULT é responsável pela publicação de uma coleção de livros intitulada Coleção CULT, em parceria com a Editora da Universidade Federal da Bahia (Edufba), e pela organização dos Encontros Multidisciplinares em Cultura (Enecult).

O primeiro livro da Coleção CULT data de 2007. Cabe ressaltar que a Coleção - que possui hoje 32 obras em seu catálogo - aborda a cultura em uma perspectiva multidisciplinar e não apenas a área das políticas culturais, embora este seja um tema bastante recorrente. Já o Enecult, que realizou sua $15^{\text {a }}$ edição em 2019, surge no ano de 2005 e constitui-se como o maior evento de discussão acadêmica sobre a cultura no Brasil. Embora possua uma temática mais abrangente, assim como a Coleção CULT, o evento se caracteriza como importante espaço de discussão acadêmica sobre políticas culturais.

O Pós-Cultura, também criado em 2005, possui cursos de mestrado e doutorado e institui-se, ao longo dos seus quase 15 anos de existência, como o mais relevante espaço de formação de profissionais e pesquisadores em políticas culturais na Bahia. Atualmente, o Programa e o CULT também são responsáveis pelo periódico eletrônico Políticas Culturais em Revista que, por sua vez,começa a publicar trabalhos na área de políticas 
culturais a partir de 2008, num primeiro momento como parte das atividades da Redepcult.

Diante do contexto ora explicitado, o projeto de pesquisa Mapeamento dos Estudos em Políticas Culturais na Bahia ${ }^{6}$ tem como objetivo direcionar o olhar para esse campo no estado, por meio de produções acadêmicas publicadas por entidades e órgãos pertencentes à UFBA, entre os anos de 2005 e 2018, a saber: artigos publicados em periódicos, livros e capítulos de livros, bem como dissertações e teses defendidas nessa instituição.

Adotamos a bibliometria como ferramenta de pesquisa, partindo do pressuposto de que a mensuração quantitativa das publicações identificadas - artigos, capítulos de livros, teses, e dissertações de autores vinculados à UFBA- revelase um indicador pertinente para analisar a produção intelectual e científica em uma área de estudos específica.

\footnotetext{
${ }^{6} \mathrm{O}$ projeto, coordenado pelos professores Renata Rocha e Leonardo Costa é desenvolvido no âmbito do OBS-CULT e do CULT-UFBA, em parceria com a Cátedra UNESCO de Políticas e Gestão Cultural, sob a responsabilidade da Fundação Casa de Rui Barbosa (FCRB).
}

\begin{abstract}
A bibliometria pode auxiliar na identificação de tendências de crescimento do conhecimento em determinada disciplina, dispersão e obsolescências de campos científicos, autores e instituições mais produtivos, e periódicos mais utilizados na divulgação de pesquisas em determinada área do conhecimento (SOARES et al., 2016, p. 177).
\end{abstract}

Desse modo, os indicadores de produção científica vêm ganhando uma importância crescente nas últimas décadas como instrumento para análise da atividade científica. A opção por adotar a Bahia como recorte espacial para compreender o desenvolvimento do campo das políticas culturais se justifica pela grande profusão de estudos neste estado, tornando-o uma referência no país, destacando-se em especial a produção intelectual oriunda da UFBA (BARBALHO; HOLANDA, 2014; SANTOS, 2017). Ademais, a proximidade institucional, acadêmica e territorial do material a ser levantado, assim como de seus autores, contribuem sobremaneira para a validação e análise contextual das informações ora levantadas.

\section{Um breve estado da arte}

Antes de nos concentrarmos nos estudos das políticas culturais na 


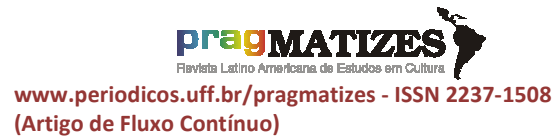

(Artigo de Fluxo Contínuo)
Bahia, propomos revisar, ainda que de maneira breve, os principais trabalhos que propõem uma análise da conformação científica do campo e seus desdobramentos. Cabe ressaltar que tais estudos têm como corpus privilegiado as práticas nos diversos setores desse campo desenvolvendo uma "análise empírica de experimentos efetivos de políticas culturais, desenvolvidas em espaços e tempos determinados" (RUBIM, 2007), com poucos estudos abordando aspectos teóricos e conceituais. Como salienta Albino Rubim (2007, p. 1),

\begin{abstract}
Pouca atenção tem sido destinada às questões mais teóricas e conceituais. Raros são os textos preocupados, por exemplo, com a teorização e a definição de políticas culturais. $\mathrm{Na}$ bibliografia nacional podem ser lembrados os textos de Teixeira Coelho e Alexandre Barbalho, que se voltam especialmente para a definição do conceito de políticas culturais.
\end{abstract}

Alguns trabalhos apontam para um esforço de articulação de pesquisadores, indicando a formação de consensos em torno de um campo de estudos comum. Dentre eles, destacamos: Estudos de política cultural no Brasil: um olhar desde o Enecult, publicado em 2014 por Alexandre Barbalho e Jocastra
Holanda; Estudos acadêmicos contemporâneos sobre políticas culturais no Brasil: análises e tendências, publicado também em 2014 por Lia Calabre; O perfil dos estudos sobre políticas culturais a partir do Enecult, de Mariella Pitombo Vieira, Leonardo Nascimento, Linda Rubim e Delmira Souza, em 2016; e, mais recentemente, a dissertação de mestrado de Marcelo Paiva Santos, intitulada Políticas culturais, um campo em formação: explorações a partir de metodologias informacionais e cientométricas.

Em Estudos de política cultural no Brasil: um olhar desde o Enecult, Barbalho e Holanda analisam nove edições do Encontro, entre os anos de 2005 e 2013.Um resultado a partir do número de publicações aponta para 402 artigos publicados que tratam de política cultural, ainda que esse não seja necessariamente o tema central.

O trabalho faz um levantamento sistemático da procedência dos autores(as) dos textos publicados; 0 nível federativo das políticas culturais - federal, estadual e/ou municipal; os agentes das políticas culturais governo, movimentos sociais, Organizações Não Governamentais 


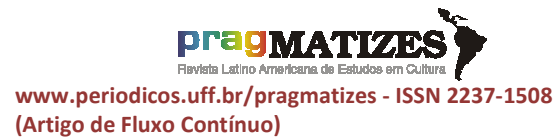

(Artigo de Fluxo Contínuo)
(ONG), empresas etc.; as perspectivas sob as quais a política cultural é discutida - patrimônio, diversidade cultural, desenvolvimento; a natureza

da abordagem - pesquisa conceitual ou pesquisas empíricas; e a identificação das disciplinas, autores(as) e livros predominantes nos trabalhos apresentados. Nos artigos apresentados, percebe-se a predominância do exame de instituições governamentais como agentes formuladores das políticas culturais. Os autores também observam que "83\% dos textos têm uma abordagem que privilegia a análise de dados empíricos" (BARBALHO; HOLANDA, 2014), corroborando com a afirmação de Rubim (2007), mencionada no presente trabalho.

$\mathrm{Na}$ pesquisa de Lia Calabre, Estudos acadêmicos contemporâneos sobre políticas culturais no Brasil: análises e tendências, as análises são focadas nas teses e dissertações da base de dados da Coordenação de Aperfeiçoamento de Pessoal de Nível Superior (CAPES), entre os anos de
1988 e $2012^{7}$, no grupo de trabalho de políticas culturais do Enecult e no Seminário Internacional de Políticas Culturais da Fundação Casa de Rui Barbosa (FCRB), ambos de 2010 e 2012.

Merece destaque, no que diz respeito às teses e dissertações, que entre os anos de 1988 e 2000, são realizados apenas 21 trabalhos indexados com as expressões eleitas para o tema de políticas culturais, de 2001 a 2012, foram encontrados 217 registros. A autora indica, ainda, um segundo movimento de aceleração de produção que tem início em 2007, ano a partir do qual o aumento do número de trabalhos seguiu uma escala crescente: 54 trabalhos de 2001 a 2006 (23\%), contra 167 trabalhos defendidos entre 2007 e 2012, alcançando um total de $77 \%$ do período (CALABRE, 2014, p. 116).È justamente em 2007que ocorre a primeira defesa do Pós-Cultura. Entre os anos de 2007 e 2012, período

\footnotetext{
${ }^{7}$ Foram trabalhados os resumos disponíveis, através de uma pesquisa a partir dos indexadores nas palavras-chave, títulos ou resumos - política cultural; políticas públicas de cultura; leis de incentivo à cultura; financiamento à cultura; e Ministério da Cultura - , ao longo de todo o período em que estiveram acessíveis na base de dados (1987 a 2012) (CALABRE, 2014, p. 114).
} 


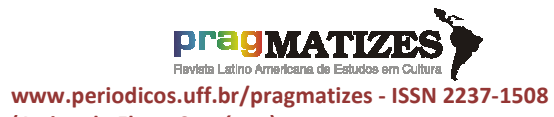

(Artigo de Fluxo Contínuo) abarcado pelo estudo de Lia Calabre, o Programa, sozinho, foi responsável por 24 teses e dissertações, ou seja, $14,5 \%$ desse total. No trabalho O perfil dos estudos sobre políticas culturais a partir do Enecult, Mariella Pitombo Vieira, Leonardo Nascimento, Linda Rubim e Delmira Souza retomam os anais do Encontro, analisando dez edições do evento, de 2005 a 2014. Através da utilização da ferramenta Atlas.ti ${ }^{8}$, são mapeados nesse escopo 2.230 trabalhos publicados. Desses, 451 trabalhos mencionam ao menos uma vez "políticas culturais"ou "política cultural", e, após refinamento com critérios estabelecidos, chegou-se ao número de 268 trabalhos com essa temática principal ou secundária. A pesquisa buscou também resultados como a titulação dos(as) autores(as) e filiação institucional, bem como temas eleitos e aporte teórico - autores(as) nacionais e internacionais citados.

$\mathrm{Na}$ direção em que já apontavam os outros estudos e em posse dos resultados da pesquisa, é defendido que

a emergência de uma agenda de pesquisa revela múltiplas camadas

\footnotetext{
${ }^{8}$ O ATLAS.ti é uma ferramenta utilizada para a análise qualitativa de grandes corpos de dados textuais, gráficos, de áudio e vídeo.
}

de processos sociais mais amplos que lhe conformam. Nesse sentido, a relevância de um tema pode sim comparecer como um termômetro das mudanças sociais que estão a se processar na sociedade (VIEIRA et al., 2016, p. 1).

Por fim, a dissertação Políticas culturais, um campo em formação: explorações a partir de metodologias informacionais e cientométricas, de Marcelo Augusto de Paiva dos Santos, utiliza a bibliometria como ferramenta para a análise das referências bibliográficas do periódico Políticas Culturais em Revista e a cientometria para identificar dados quantitativos de pesquisadores da área, adotando a Plataforma Lattes como eixo de investigação, capaz de indicar

possíveis aspectos constitutivos da área de pesquisa, como os marcos teóricos que são aventados para construir sua narrativa enquanto objeto de estudo, bem como os tipos de trajetórias acadêmicas que os pesquisadores perfomam, permeadas pelos tópicos que compõe a área de pesquisa em apreço (SANTOS, 2017, p. 17).

O trabalho, pioneiro no campo das políticas culturais, busca identificar e relacionar elementos relevantes para a produção de conhecimento, a exemplo dos autores citados nos artigos da revista e as principais características das redes de 


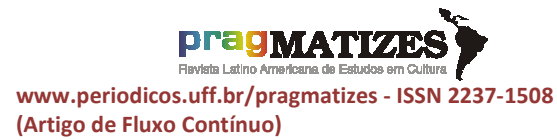

(Artigo de Fluxo Contínuo) pesquisadores que indexam a área na Plataforma Lattes.

Se, por um lado, as reflexões anotadas neste breve "estado da arte" dos trabalhos que se dedicam à produção de conhecimento em políticas culturais trazem aportes relevantes para o desenvolvimento do estudo ora proposto, por outro, o pioneirismo destes aponta para a necessidade de realização de novas pesquisas, a fim de aprimorar metodologias e perspectivas e corroborar os seus resultados.

\section{Explorações bibliométricas}

Conforme mencionado, para a realização deste trabalho, optamos pela bibliometria, método de análise quantitativa para a pesquisa científica, no qual os dados levantados mensuram a contribuição do conhecimento científico derivado das publicações em determinadas áreas. Além disso, tais informações podem ser utilizadas na representação das atuais tendências de pesquisa e na identificação de temas para novas pesquisas.

A pesquisa previa, inicialmente, a realização de um levantamento de trabalhos monográficos para obtenção de graus - monografias, teses e dissertações sobre políticas culturais - defendidos em instituições de ensino baianas, entre os anos de 2005 e 2018, além de livros, capítulos e artigos publicados em periódicos, cujos autores e/ou co-autores possuem vinculação institucional com órgãos sediados na Bahia (2005$2018)^{9}$. No entanto, diante da pouca expressividade numérica da produção bibliográfica externa à UFBA, optamos pela delimitação a essa instituição de ensino.

Embora tenham sido levantadas as monografias de graduação, ou trabalhos de conclusão de curso, apresentadas na UFBA, os dados não foram apresentados neste artigo, devido à baixa expressividade de trabalhos localizados. Mais do que discutir a representatividade desse número, supomos que a pesquisa sobre as políticas culturais, pelo menos na Bahia, tem um destaque maior na pós-graduação, inclusive na lato sensu, do que na graduação. Das

\footnotetext{
${ }^{9}$ Optamos por realizar o levantamento dos artigos publicados em anais de eventos acadêmicos em etapa posterior, ora em curso.
} 


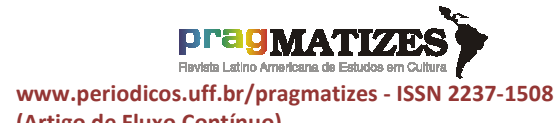
(Artigo de Fluxo Contínuo)
32 monografias pesquisadas no

Repositório Institucional (RI) da UFBA, apenas 13 foram apresentadas na universidade, provenientes do curso de Comunicação com habilitação em Produção em Comunicação e Cultura. As 19 restantes foram apresentadas como requisito para conclusão do curso lato sensu de formação de Gestores Culturais dos Estados do Nordeste, um programa pontual realizado em parceria entre o Instituto de Humanidades, Artes e Ciências Professor Milton Santos (Ihac), o então Ministério da Cultura (MinC) e a Fundação Joaquim Nabuco (Fundaj).

Em todos os objetos do levantamento, foi adotada como elemento de localização a existência do termo "políticas culturais" e suas múltiplas variantes ${ }^{10}$ por meio da autoindexação pelo autor, considerando: (1) palavras-chave, (2) títulos e/ou (3) resumos. Quanto a esse aspecto, tomamos como referência a metodologia proposta por Marcelo de Paiva Santos (2017).

\footnotetext{
${ }^{10}$ Os termos utilizados foram: política cultural, políticas culturais, política pública de cultura, políticas públicas de cultura, política pública cultural, políticas públicas culturais, política para a cultura, políticas para a cultura, política de cultura, políticas de cultura, política para cultura e políticas para cultura.
}

Seguindo as pegadas desse autor, escolhemos tão somente variações da expressão "políticas culturais" mas, em contraponto, optamos por uma maior abrangência nos locais de busca para além das palavras-chave. Por fim, a escolha do ano de 2005 como ponto de partida toma como parâmetro a criação do Pós-Cultura, tendo em vista o impacto do programa para a produção sistemática de conhecimento sobre políticas culturais na UFBA.

Cabe explicitar que as tipologias das publicações levantadas possuem especificidades que os influenciam sobremaneira. Como exemplos, podemos citar: a exigência de que pelo menos um autor seja doutorando ou tenha 0 título de doutor para publicação no periódico Políticas Culturais em Revista; as diferenças em termos de investimento acadêmico para o desenvolvimento de uma tese ou dissertação, em contraposição a um capítulo de livro; ou ainda as disparidades das bases informacionais e métodos de busca, dentre outras explicitadas a seguir. Ou seja, embora representem um conjunto que contribui para ilustrar o campo dos estudos em 


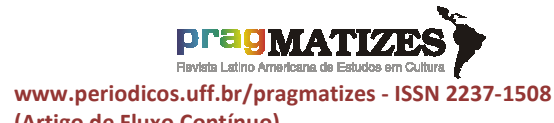

(Artigo de Fluxo Contínuo) políticas culturais na Bahia, os dados não podem ser comparados entre si.

\section{Capítulos de livros}

O levantamento de capítulos de livros adotou como base o $\mathrm{Rl}$ da UFBA $^{11}$, com foco nas publicações produzidas pelo CULT ou em parceria com o Centro, a saber: Coleção CULT, Cultura e Pensamento e Sala de Aula. A fim de abarcar outras publicações , foi feita uma pesquisa na seção de "coleções" do Repositório com o termo "políticas culturais"e termos afins, no intuito de saber quais os livros que traziam capítulos sobre a temática.

Para traçar um panorama da natureza das publicações e de sua autoria, elencaram-se os seguintes itens: título, ano da publicação, nome do(a) autor(a) e co-autor(a), bem como dados sobre sua formação - titulação da última formação, instituição e estado. No caso dos capítulos, as palavras-chave não foram catalogadas, pois elas só fazem parte dos dados presentes na contracapa dos livros.

\footnotetext{
${ }^{11}$ Disponível em: https://repositorio.ufba.br/ri/. Acesso: 9 abr. 2019.
}

Foram identificados 154 capítulos de livros ${ }^{12}$ publicados nas edições do CULT entre os anos de 2005 e 2018, somando o total de 224 autores e autoras - entre autoria e co-autoria. São computados(as) de forma múltipla autores (as) que possuem publicações distintas. Há uma predominância de autoria individual, em 104 capítulos (67,5\%). Em relação ao gênero, não se verifica grande disparidade , sendo 105 homens (46,9\%) e 119 mulheres $(53,1 \%)$.

Ao considerar a distribuição temporal, 2010 se destaca, ao contar com 34 capítulos publicados, conforme o Gráfico 1. Vale ressaltar que, no ano em questão, três livros se dedicaram às políticas culturais. São eles: Políticas culturais no governo Lula, organizado por Antonio Albino Canelas Rubim; Políticas culturais para as cidades, organizado por Antonio Albino Canelas Rubim e Renata Rocha; e Políticas culturais, democracia e

\footnotetext{
${ }^{12} \mathrm{O}$ livro Políticas culturais na Bahia contemporânea, de Antonio Albino Canelas Rubim, diferente de todos os livros catalogados, não se trata de uma coletânea de capítulos, mas um relato sobre a experiência do autor frente à Secretaria de Cultura do Estado da Bahia. Para fins metodológicos, contudo, o livro foi catalogado como os outros capítulos.
} 
conselhos de cultura, organizado por Rubim e Taiane Fernandes.

Antonio Albino Canelas Rubim, luri

Gráfico 1: Número de capítulos sobre políticas culturais publicados em livros por ano

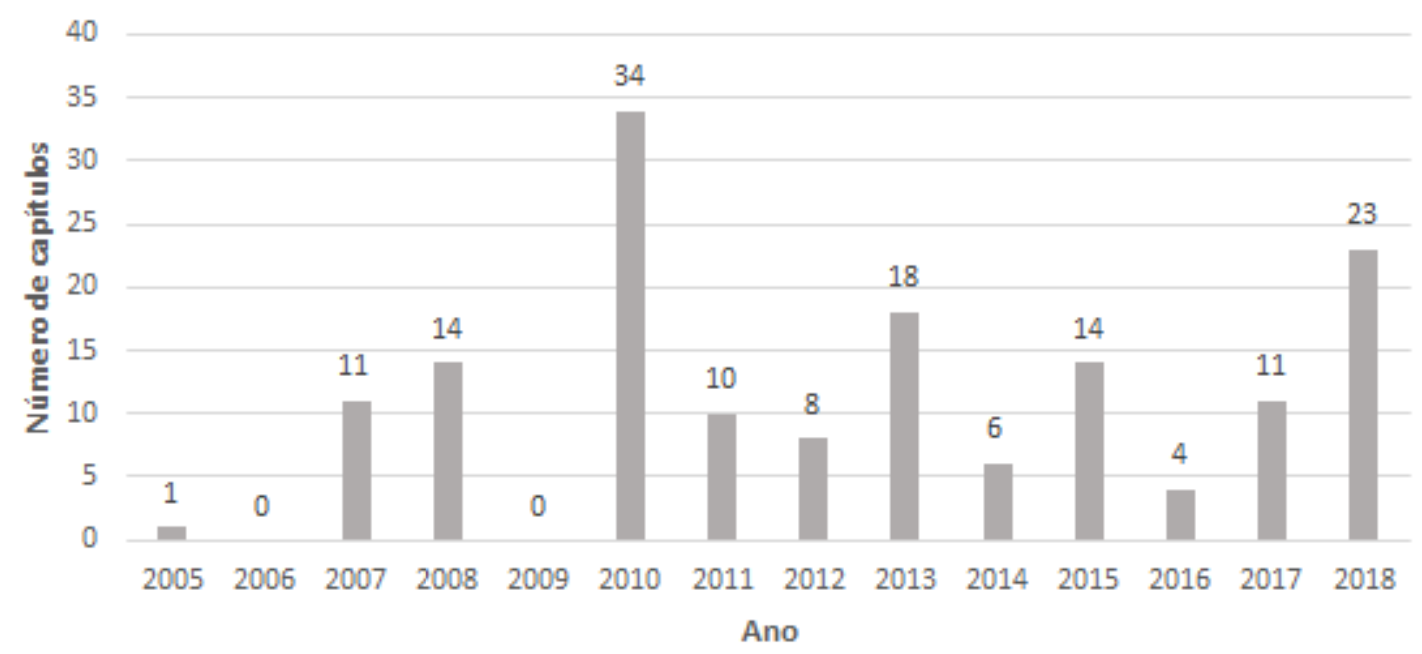

Fonte: elaborado pelos autores.

Em relação à titulação, destacase a alta qualificação: $76,8 \%$ dos autores e autoras que assinam os textos possuem nível de pósgraduação (lato e stricto sensu ${ }^{13}$ ). Destes, 49,1\% são doutores(as), conforme Gráfico 2. Verifica-se a presença de graduandos ou graduados no levantamento, demonstrando a importância da iniciação científica no processo

\footnotetext{
${ }^{13}$ Para informações sobre lato (programas de especialização) e stricto sensu (programas de mestrado e doutorado):

http://portal.mec.gov.br/component/content/ar ticle?id=13072:qual-a-diferenca-entre-posgraduacao-lato-sensu-e-stricto-sensu. Acesso: 9 jun. 2020.
}

inaugural de formação do futuro pesquisador. Cabe ressaltar, ainda, que a ordem das categorias de titulação do Gráfico 2 seguem a grandeza dos dados, e não a hierarquia das titulações. 


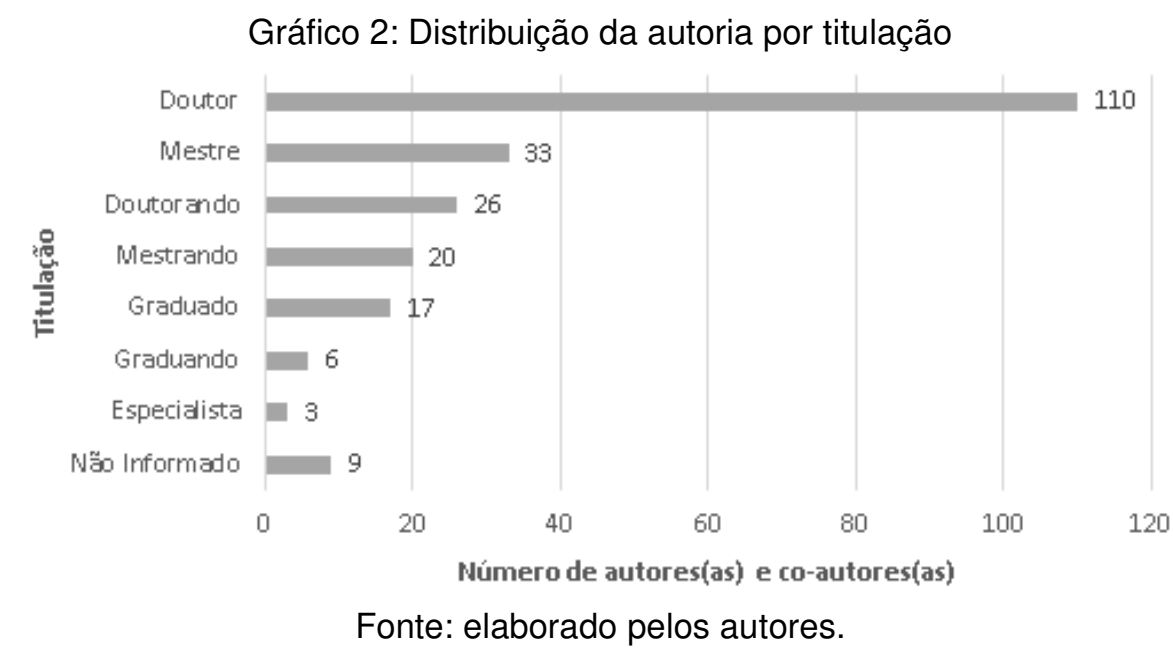

A Bahia se destaca em relação à autoria por estado, com 95 autores $\mathrm{e}$ autoras $(42,4 \%)$, seguido do Rio de Janeiro com 23 (10,3\%) e São Paulo com 19 (8,5\%). Dado consoante ao encontrado por Alexandre Barbalho e Jocastra Holanda (2014, p. 164) ao ressaltarem a procedência dos 402 artigos que tratam sobre políticas culturais no Enecult: elevada concentração nos estados da Bahia, Ceará, Rio de Janeiro e São Paulo. Chama a atenção, ainda, a grande quantidade de autores(as) estrangeiros(as), relativa a $10,7 \%$ do total, oriundos, em sua maioria de países da América Latina e Europa.

Gráfico 3: Distribuição territorial da autoria, considerando a instituição de vínculo da formação mais recente ou em curso 


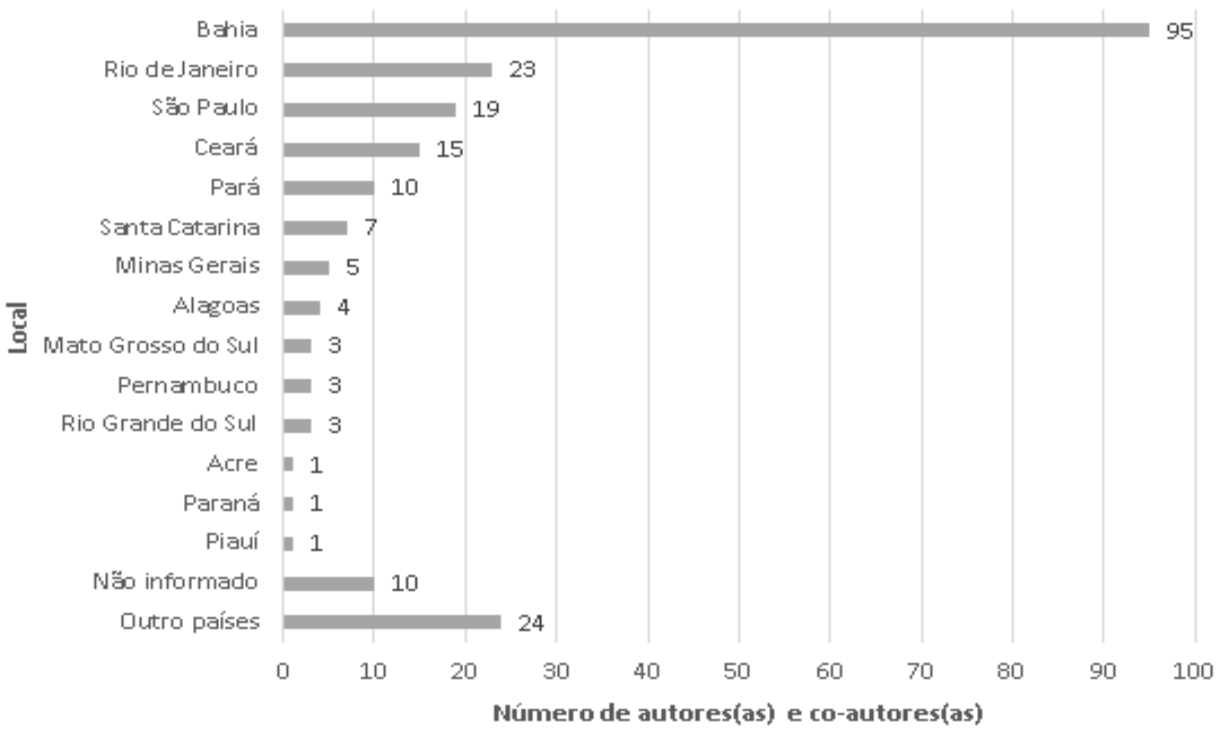

Fonte: elaborado pelos autores.

Em relação às instituições de vínculo, a UFBA representa uma fatia significativa dentre os responsáveis pela produção dos textos: são 76
(33,9\%) formados(as) ou em formação pela UFBA, dos quais 30 são oriundos(as) do Pós-Cultura, conforme explicita o Gráfico 4.

Gráfico 4: Distribuição da autoria por instituição de vínculo da formação mais recente ou em curso

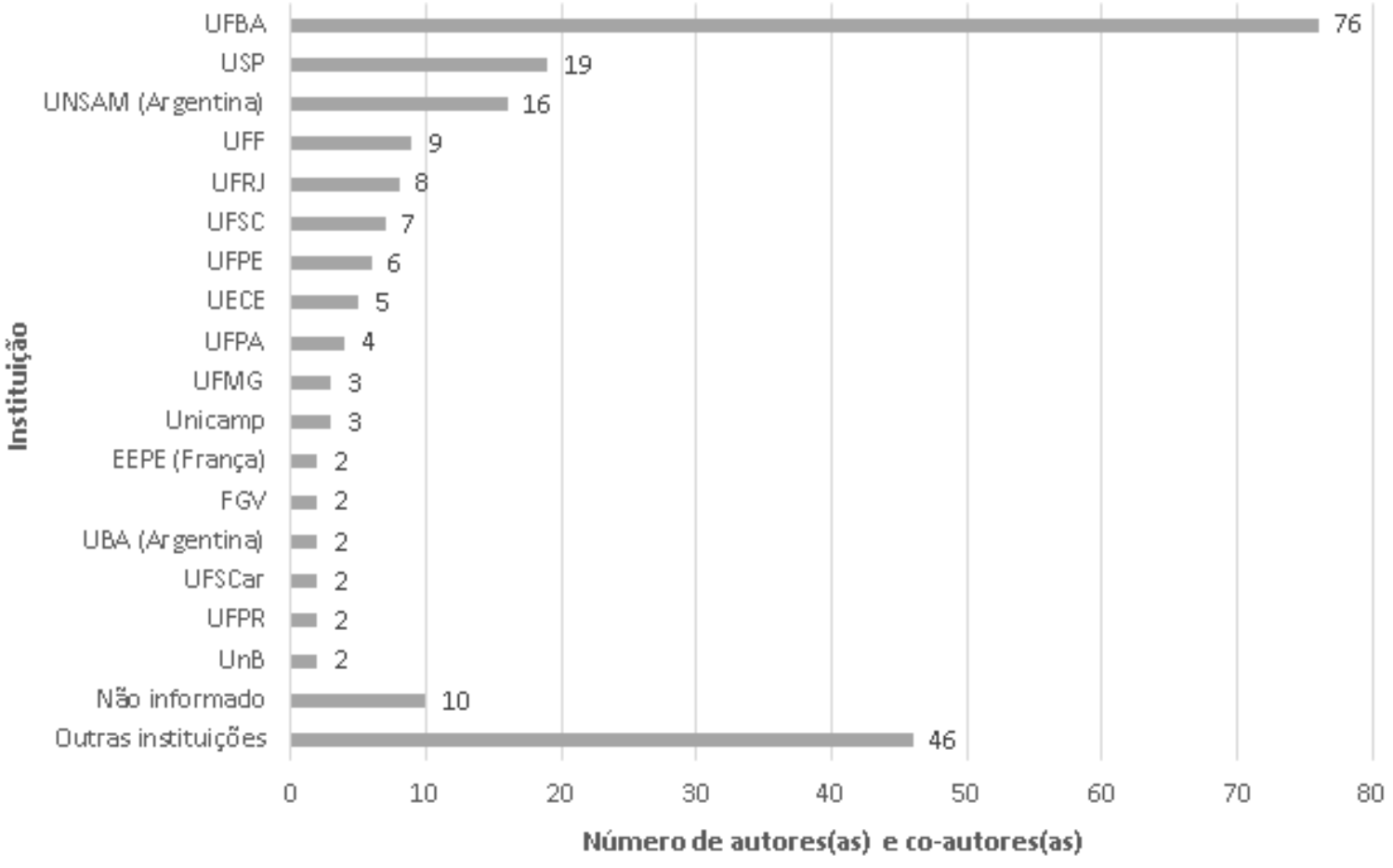


Fonte: elaborado pelos autores.

A superioridade numérica da autoria baiana e de professores e estudantes vinculados à UFBA não surpreende e pode ser explicada por um conjunto de fatores. Num primeiro momento, o fato de os livros serem publicados e lançados pela Edufba, editora da universidade, em conjunto com o CULT, impulsionam a maior participação de pessoas próximas a essas instituições. Outro aspecto, não menos relevante, é o papel de referência do CULT e do Pós-Cultura, conforme já mencionado, nos estudos contemporâneos das políticas culturais. Da mesma forma, ao analisar os artigos sobre políticas culturais do Enecult, Barbalho e Holanda (2014, p. 164)verificam que a UFBA é a instituição de vínculo de $83 \%$ dos autores(as), com significativa presença de estudantes do Pós-Cultura. Por outro lado, conforme asseveram Vieira e colaboradores (2016, p. 5), a expressiva participação de autores(as) da UFBA pode indicar o grau de endogenia, perspectiva que parece adequada para interpretar os dados ora apresentados. Por fim, cabe ressaltar que, para além de estudiosos já reconhecidos no campo, muitos capítulos são assinados coletivamente ou não - por pesquisadores em formação, conforme sugere o Gráfico 2.

\section{Levantamento dos artigos em periódicos}

O levantamento de artigos sobre políticas culturais em periódicos tomou como base o Portal de Periódicos da UFBA ${ }^{14}$. A metodologia utilizada, semelhante à seleção dos capítulos no $\mathrm{Rl}$ dessa mesma instituição, localizou textos dedicados à temática em periódicos como: Cadernos CRH (Centro de Recursos Humanos), Revista Interdisciplinar de Gestão Social e DANÇA: Revista de Pós-Graduação em Dança. Foi dada especial atenção, porém, à Políticas Culturais em Revista, devido à robustez do material disponibilizado, consequência do foco em políticas culturais e da relevância da publicação para essa área de estudos, conforme atestado por Santos (2017).

\footnotetext{
${ }^{14}$ Disponível em: https://portalseer.ufba.br/. Acesso: 10 abr. 2019.
} 
Após o levantamento prévio, foi feito um tratamento dos textos em busca dos termos afins ao de "políticas culturais" (ver nota de rodapé $n^{\circ} 8$ ), localizados nos títulos, nos resumos e nas palavras-chave. Foram encontrados 157 artigos, escritos por 243 autores(as) e co-autores(as) mais uma vez computando de forma múltipla a reincidência de participações -, entre 2008, ano da primeira publicação da Políticas Culturais em Revista ${ }^{15}$, e 2018. Ao longo do período, destaca-se o ano de 2015, com 28 artigos publicados, conforme o Gráfico 5.

\footnotetext{
${ }^{15}$ Nenhum outro periódico baiano apresentou publicações no anos anteriores com os termos buscados e com base nos critérios escolhidos para o mapeamento.
} 
Gráfico 5: Número de artigos sobre políticas culturais publicados em periódicos por ano

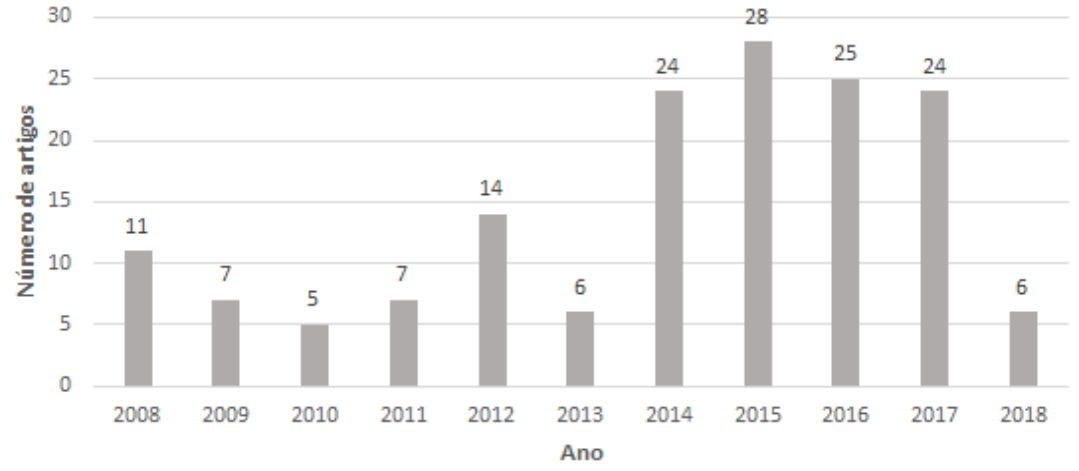

Fonte: elaborado pelos autores.

A maioria teve autoria individual, num total de 92 artigos (58,6\%). Quanto ao gênero, as mulheres estão em maior número, correspondendo a 154 participações (63,4\%). Doutores(as) são maioria, correspondendo a 139 ocorrências $(57,2 \%)$, mais que a metade. Destacase também a presença de mestres(as) e doutorandos(as) nos artigos, sendo 38 cada, que juntos somam 31,3\%, como demonstra o Gráfico 6.

O alto nível de titulação pode ser explicado pelo fato de que os periódicos, via de regra, exigem em suas normas de submissão que pelo menos um dos autores(as) seja doutor(a) ou doutorando(a).

Gráfico 6: Autores e autoras que publicaram artigos sobre políticas culturais em periódicos na Bahia, de 2005 a 2018, por titulação

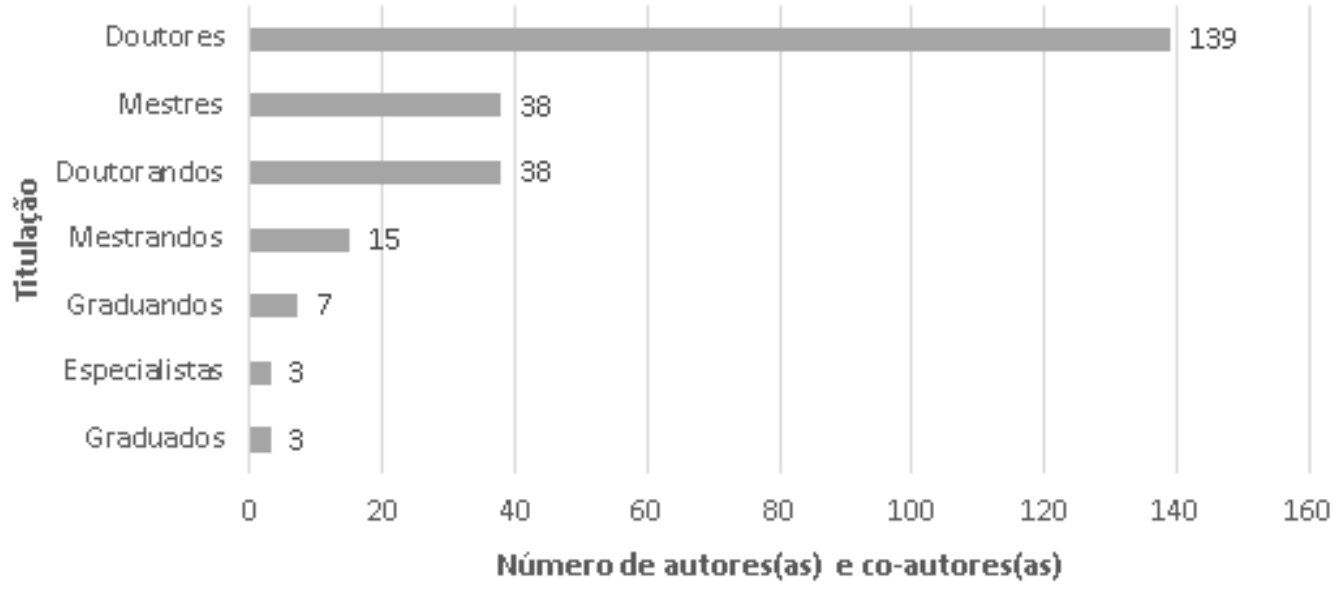

Fonte: elaborado pelos autores. 
No que se refere à unidade Universidade Federal do Rio de federativa onde se encontram Janeiro (UFRJ) com 13 (5,3\%), como vinculados(as) os(as) autores(as), o apresentado no Gráfico 7. Cabe estado com o maior número é o Rio de Janeiro, com 46 (18,9\%), seguido por São Paulo, com $32(13,2 \%)$ e pela destacar aqui o segundo lugar da UFF na lista, muito possivelmente pelo fato de a universidade sediar um dos Bahia, com 31 (12,8\%). Em relação às cursos pioneiros de graduação na área universidades em que realizaram sua última titulação, a UFBA formou 31 autores(as) (12,8\%), seguida pelas Universidade Federal Fluminense (UFF), com 17 (7\%), Universidade de de produção cultural no país. Além disso, há uma grande diversidade: $31,7 \%$ dos dados se referem a instituições com uma ou duas ocorrências.

São Paulo (USP) com 16 (6,6\%) e

Gráfico 7: Distribuição do número de autores que publicaram artigos sobre políticas culturais em periódicos da UFBA, de 2005 a 2018, por instituição vinculada (formados ou em formação)

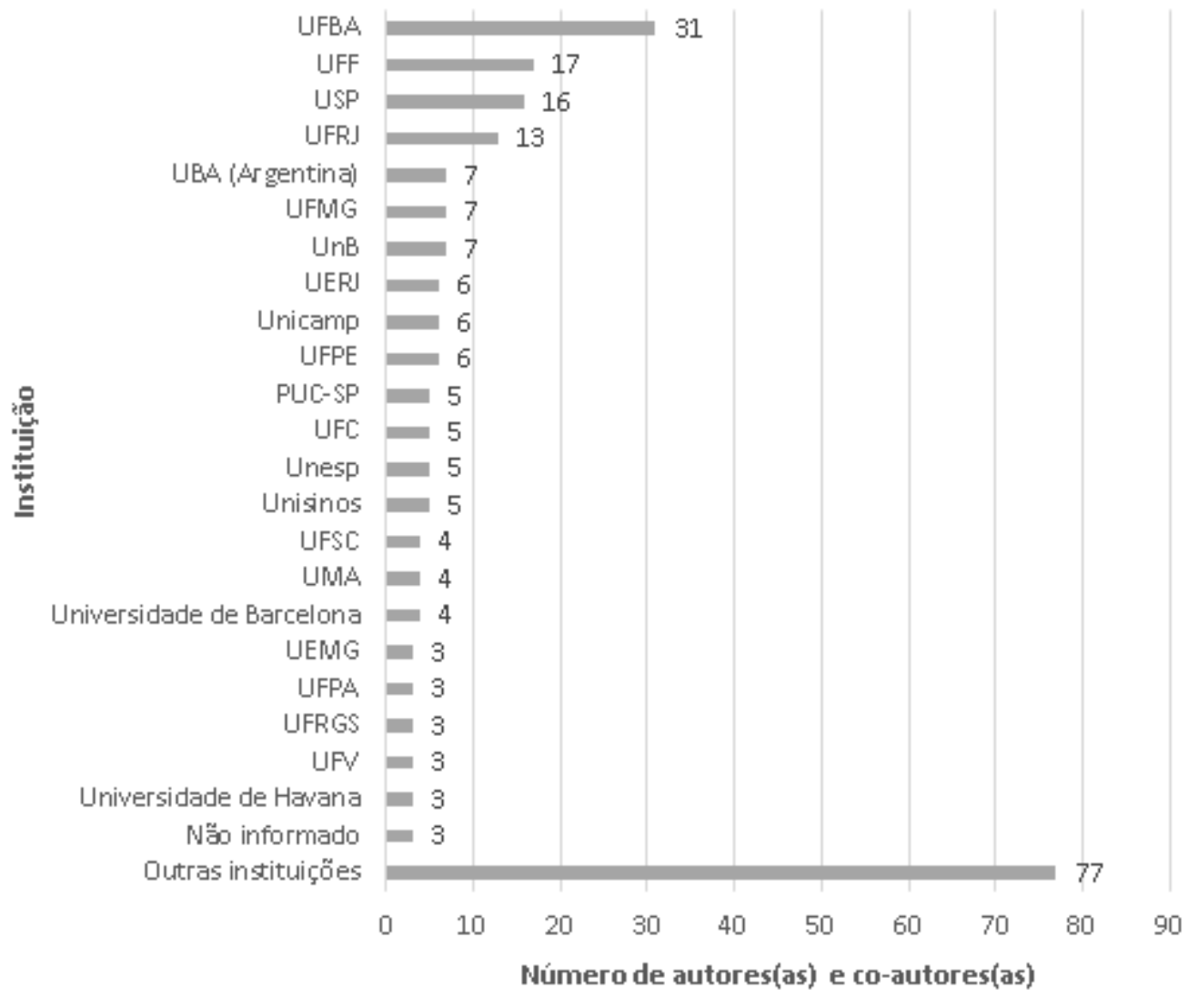

Fonte: elaborado pelos autores. 
Verifica-se a pertinência entre os estados $\mathrm{e}$ as universidades da última titulação Os três estados com maior número de autores(as) devem sua colocação a instituições que também figuram nas primeiras posições.

\section{Levantamento de teses e dissertações}

Para levantamento bibliométrico das teses e dissertações, foram utilizados os bancos de dados do $\mathrm{RI}$ da $\mathrm{UFBA}^{16}$ e o Catálogo de Teses e Dissertações da Capes ${ }^{17}$. Buscamos novamente pelo termo "políticas culturais"e suas múltiplas variantes em três diferentes campos dos trabalhos encontrados, a saber: título, resumo e palavras-chave. Inicialmente, o escopo do trabalho previa um levantamento apenas no Pós-Cultura, mas, ao longo das pesquisas, identificou-se a importância de ampliar o escopo para outros programas de pós-graduação da UFBA, no intuito de avaliar a

\footnotetext{
${ }^{16}$ Disponível em: https://repositorio.ufba.br/ri/. Acesso:9 abr. 2019.

${ }^{17}$ Disponível em: https://catalogodeteses.capes.gov.br/catalog o-teses/\#!/. Acesso: 9 abr. 2019.
}

multidisciplinaridade da área, além de buscar uma maior abrangência e representatividade.

No que diz respeito às teses e dissertações, em que pese a proximidade temática e metodológica quanto ao corpus ora analisado com o da pesquisa de Lia Calabre (2014), não é possível adotar uma perspectiva comparativa entre ambos, tendo em vista as diferenças quanto à eleição dos termos de busca, dos recortes territoriais e temporais, bem como pela junção, ou não, dessas duas tipologias de trabalhos. Entretanto, consideramolo, conforme explicitado, uma relevante referência. Aqui, conforme se depreende, optou-se por dissociar as teses das dissertações. Focaremos, por ora, nas primeiras. De 2005 a 2018, foram publicadas 34 teses de doutorado sobre o tema na UFBA, conforme explicitado pelo Gráfico 8. 
Gráfico 8: Distribuição do número de teses defendidas sobre políticas culturais, de 2005 a 2018, por programas de pós-graduação da UFBA

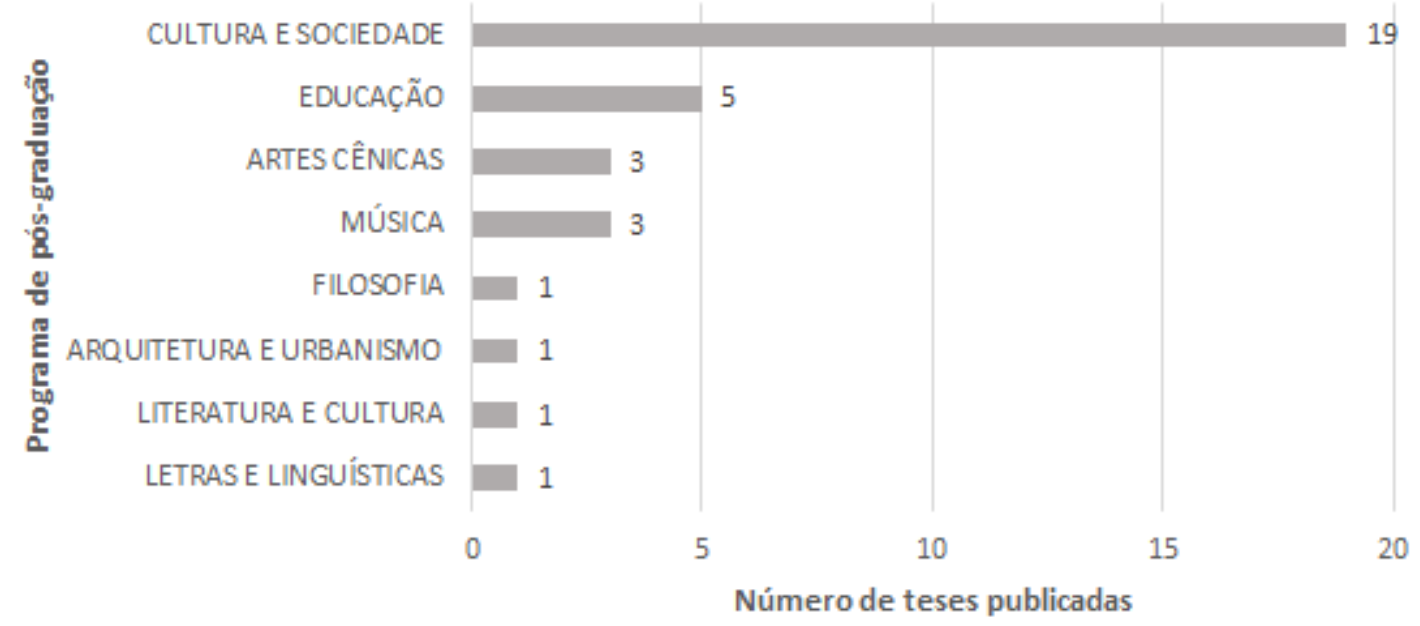

Fonte: elaborado pelos autores.

O Pós-Cultura só passa a teses (56\%) até 2018, com destaque figurar em nossa análise a partir de nos anos de 2013 e 2017, com 4 e 5 2010, visto que sua criação se dá em teses publicadas, respectivamente. 2005, mas ainda assim apresenta 19

Gráfico 9: Número de teses defendidas sobre políticas culturais, de 2005 a 2018, no Pós-Cultura por ano, em relação a outros programas de pós-graduação da UFBA

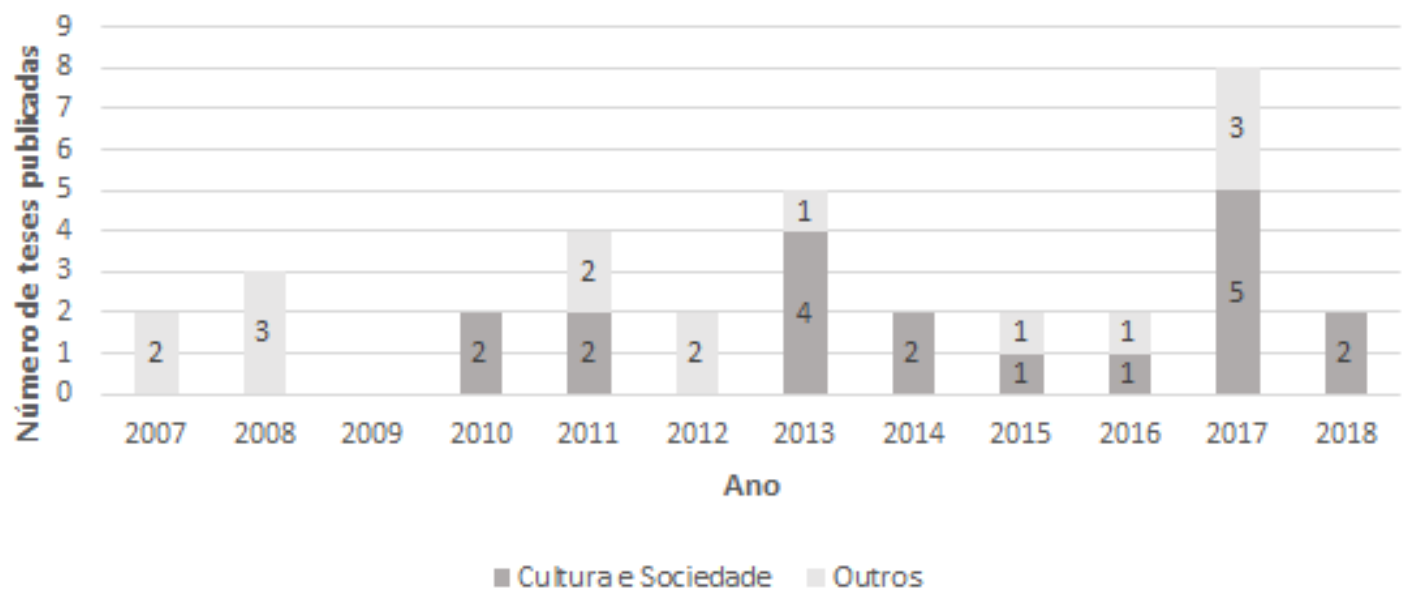

Fonte: elaborado pelos autores. 
As outras 15 teses defendidas na UFBA, de 2005 a 2018, distribuemse nos programas de Educação, Artes Cênicas, Música, Filosofia, Arquitetura e Urbanismo, Literatura e Cultura e Letras e Linguísticas. Isso, de algum modo, atesta a multidisciplinaridade assinalada por Lia Calabre (2014) e reiterada por Marcelo de Paiva Santos (2017). Este último, ao se debruçar sobre os currículos Lattes de pesquisadores identificados como pertencentes ao campo das políticas culturais, encontra indícios de multidisciplinaridade não apenas no que diz respeito à formação acadêmica - multidisciplinaridade vertical - , como também no que diz respeito à conectividade por similaridade semântica entre eles, visto que não se verifica uma semantização curricular homogênea e uma maior interação entre esses estudiosos.

Com relação aos termos eleitos, 24 trabalhos fizeram menção a "políticas culturais"em seus títulos, resumos e/ou palavras-chave. O termo "política cultural"foi utilizado em 18 trabalhos, "políticas de cultura" em 3, "políticas públicas de cultura" em 2 e "políticas públicas culturais" em 1 publicação. As outras expressões não foram identificadas em quaisquer trabalhos.

Gráfico 10: Número de teses sobre políticas culturais por termo eleito pelo autor(a)

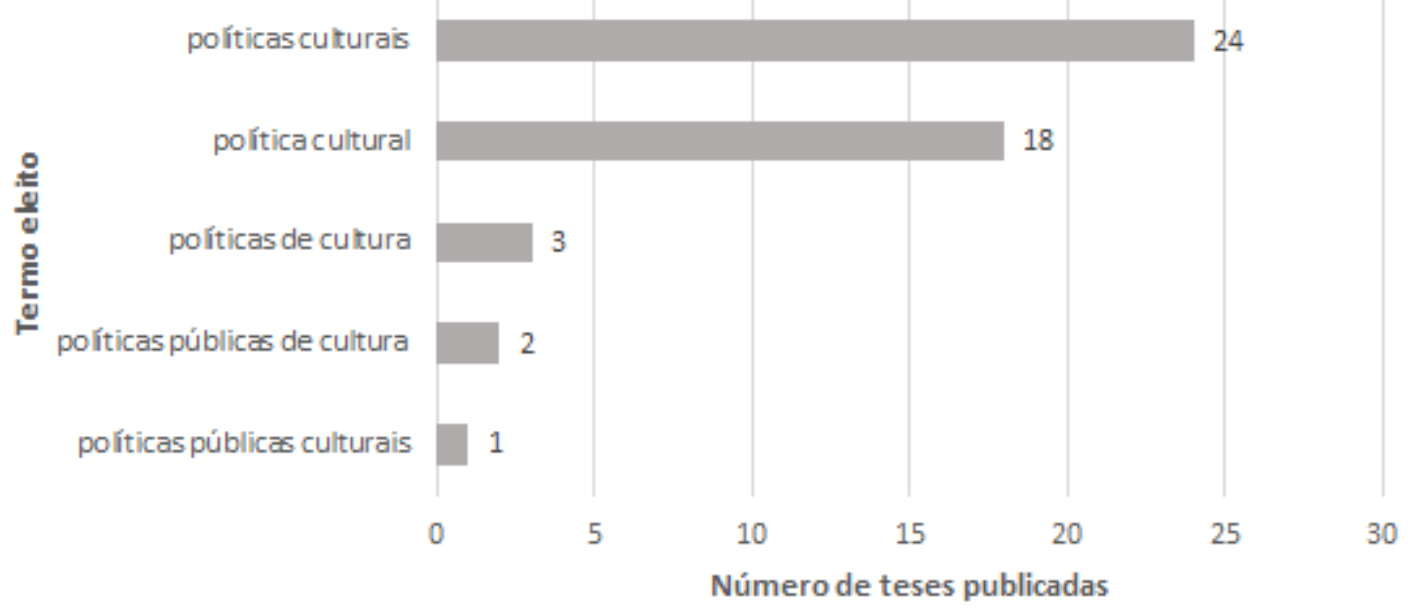

Fonte: elaborado pelos autores. 
Podemos atribuir a preponderância do termo "políticas culturais"ao fato de ser o modo mais comumente denominado nos estudos e pesquisas realizados na Bahia, conforme dados catalogados nas publicações da Coleção CULT, por exemplo.
Quanto às dissertações de mestrado, estas representam quase 0 dobro de trabalhos em relação às teses de doutorado. No total, as dissertações que versam sobre o tema das políticas culturais entre 2005 e 2018 somam 59 publicações. Dessas, 40 (68\%) são oriundas do Pós-Cultura, conforme o Gráfico 11.

Gráfico 11: Distribuição do número de dissertações sobre políticas culturais defendidas de 2005 a 2018, por programas de pós-graduação da UFBA

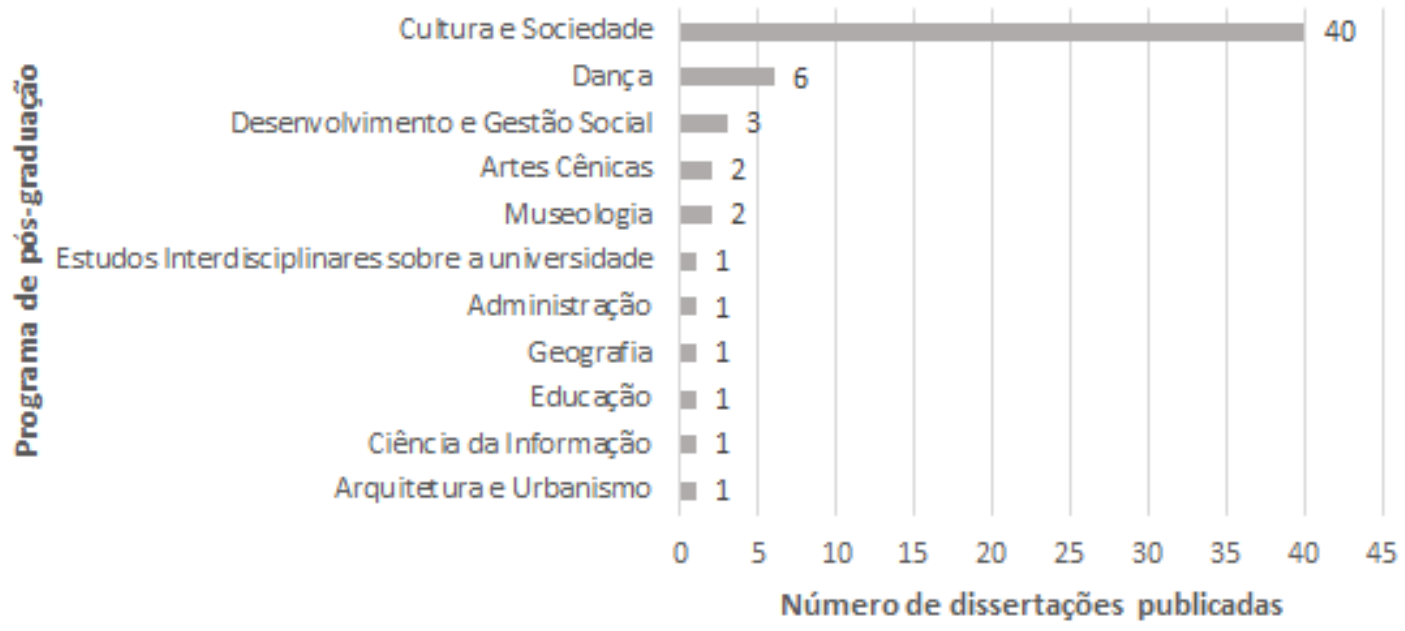

Fonte: elaborado pelos autores.

Desde sua primeira defesa, em 2007, o programa já conta com trabalhos na área, com destaque para os anos de 2013, com oito dissertações, 2017 e 2018 com cinco cada um. Temporalmente, é possível que a concentração de trabalhos sobre o tema no ano de 2013 seja uma decorrência da ampliação das políticas públicas para a cultura implementadas nos governos Lula (2003-2010), como descrito anteriormente neste trabalho. As demais 19 dissertações distribuemse em outros dez programas. 
Gráfico 12: Distribuição do número de dissertações sobre políticas culturais defendidas de 2005 a 2018, no Pós-Cultura, em relação a outros programas de pós-graduação da UFBA por ano

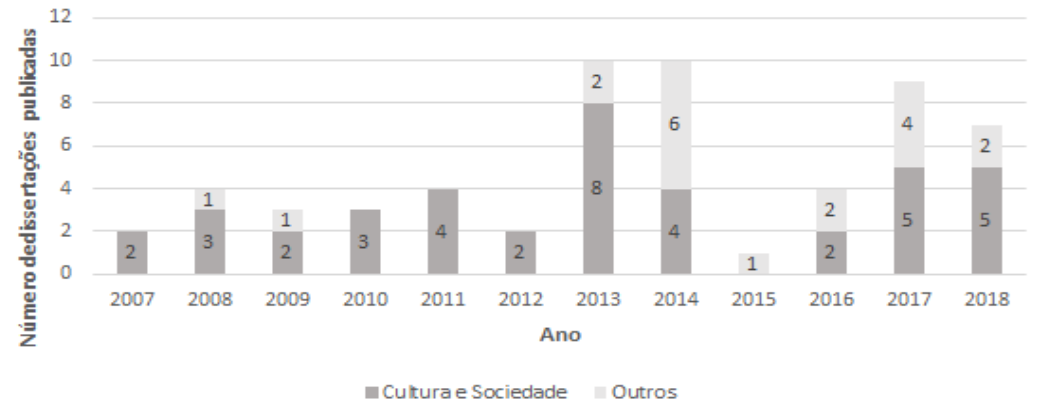

Fonte: elaborado pelos autores.

Quanto à nomenclatura utilizada, verifica-se novamente a predominância no uso de "políticas culturais"em 43 trabalhos, seguido por "política cultural" em 27, "políticas públicas de cultura" em 7, "políticas públicas culturais" em 6, "política pública de cultura" em dois, e "políticas para a cultura" e "políticas de cultura" em 1 trabalho cada. As outras expressões utilizadas para delimitação não foram identificadas.

Gráfico 13: Distribuição do número de dissertações por termo presente em seus títulos, resumos e/ou palavras-chave

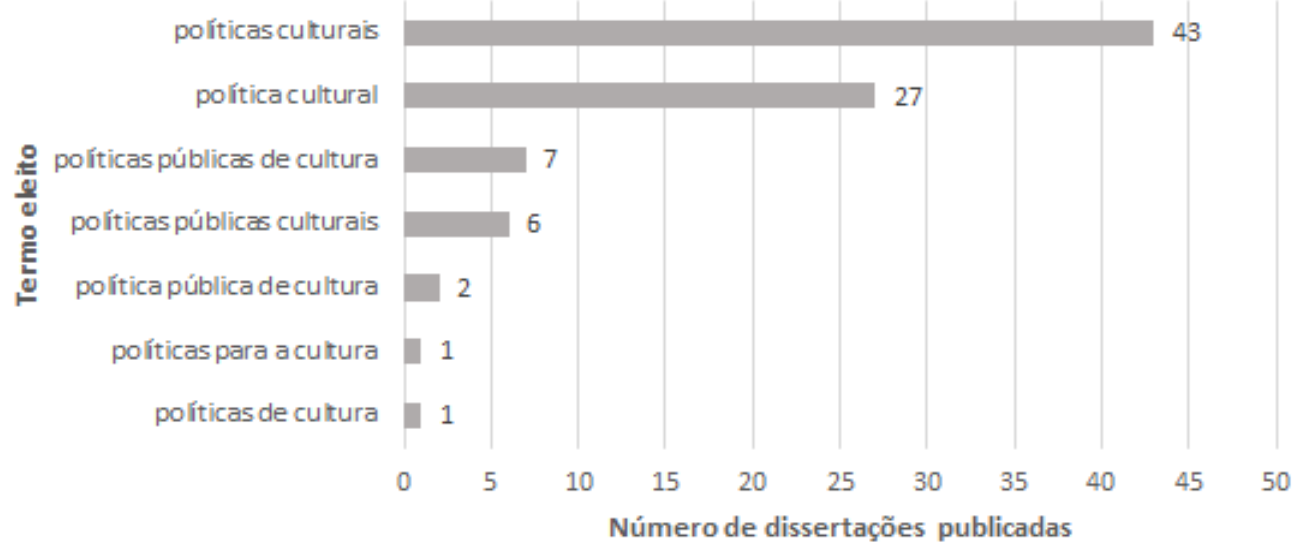

Fonte: elaborado pelos autores.

A respeito dos termos eleitos, assinalamos, por fim, a relevância do uso de um largo espectro de expressões variantes das políticas culturais. Apenas a título de exemplo, Calabre (2014, p. 116) encontra, entre 
os anos de 2007 e 2012, 63 teses e dissertações com a expressão "política pública de cultura", em títulos, resumos ou palavras-chave, sendo este o termo com maior recorrência, seguido por "Ministério da Cultura" (57), "leis de incentivo" (30), "política cultural" (12) e "financiamento à cultura" (5). Já em nossa sistematização, porém, o termo mais referenciado nas teses e dissertações foi "políticas culturais". Tal dado pode indicar uma maior expressividade da produção científica em nível de pósgraduação no campo do que a identificada pela autora. Por sua vez, também é possível que a sistematização ora apresentada tenha o seu alcance reduzido por não utilizar termos que possam indicar uma afinidade com as políticas culturais. Tal opção considerou que a adoção explícita de qualquer uma das expressões variantes indicaria 0 sentimento de pertença à área por parte dos pesquisadores e pesquisadoras.

\section{Considerações}

Como primeiro resultado do projeto Mapeamento dos Estudos em Políticas Culturais na Bahia, optou-se pelo levantamento de modalidades distintas de atuação e inserção no campo. É interessante notar que, dadas as características singulares de cada tipo de produto, são identificadas diferenças bastante significativas entre eles. Tais distinções dizem respeito ao tempo de produção, extensão, aprofundamento e exigências para submissão e/ou publicação. Por esse motivo, não se pretende aqui comparálos, mas apresentar um panorama bastante abrangente e diversificado da produção científica desenvolvida no estado.

As diferenças nos dados trazem aspectos que merecem ser comentados. Enquanto, nos capítulos de livros, há um destaque massivo de autores(as) baianos(as) e formados(as) pela UFBA em relação aos demais estados e universidades, nos artigos do periódico, a origem territorial da autoria é dividida com Rio de Janeiro e São Paulo, e suas respectivas universidades. Ou seja, ainda que ambas as publicações sejam vinculadas ao CULT-UFBA, as diferenças no modo como são divulgadas as chamadas, nos critérios de seleção de textos e na organização e edição dos materiais explicam a 


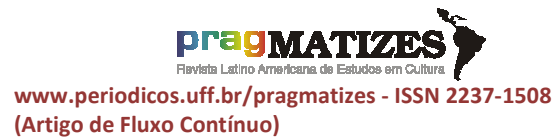

(Artigo de Fluxo Contínuo) diferença entre os dados obtidos. Cabe ressaltar que, na publicação de artigos em periódicos, há uma chamada pública para submissão em fluxo contínuo e a avaliação é feita por pares, fato normalmente não observado na organização dos livros. A publicação em periódicos também possui um maior impacto se forem considerados os sistemas vigentes de avaliação para professores vinculados a programas de pós-graduação.

Por sua vez, merece destaque 0 fato de que, dos 93 autores(as) mapeados(as) nas dissertações e teses, 40 (43\%) concluíram a sua graduação na própria UFBA. Isso demonstra que há uma certa continuidade na instituição de formação acadêmica, embora se verifique a existência de trajetórias de cunho multidisciplinar, com distinções entre as áreas dos cursos de graduação e pós-graduação. Os(as) outros(as) autores(as) concluíram a sua graduação em instituição como Universidade Salvador (Unifacs), Universidade Federal da Paraíba (UFPB), Universidade de Fortaleza (Unifor), dentre outras.

Conforme já explicitado, o principal objetivo da pesquisa em curso é verificar de que modo os estudos sobre as políticas culturais se desenvolvem na Bahia, e, por sua relevância para o campo no estado, optamos por enfatizar a produção oriunda da UFBA. Nesse sentido, encerrada a parte quantitativa, 0 projeto vem se dedicando à sistematização dos dados obtidos, com o propósito de ampliar o conjunto a ser analisado e ao mesmo tempo aprofundar a reflexão sobre a área, atendo-se a aspectos como os temas eleitos, as abordagens metodológicas envolvidas, os conceitos de políticas culturais acionados, as experiências de políticas examinadas, a bibliografia e conjunto documental específicos e outras questões que certamente emergirem desse profícuo corpus.

\section{Referências bibliográficas}

BARBALHO, Alexandre. Política cultural: um debate contemporâneo. In: RUBIM, Linda. Organização e produção da cultura. Salvador: Edufba, 2005. p. 33-52.

BARBALHO, Alexandre; HOLANDA, Jocastra. Estudos de política cultural no Brasil: um olhar desde o ENECULT. In: RUBIM, Linda Silva Oliveira; VIEIRA, Mariella Pitombo; SOUZA, Delmira Nunes de (orgs.). Enecult 10 anos. Salvador: Edufba, 2014. p. 183196. 
CALABRE, Lia. Estudos acadêmicos contemporâneos sobre políticas culturais no Brasil: análises e tendências. Pragmatizes: Revista Latino-Americana de Estudos em Cultura, Niterói, n. 7, p. 109-129, set. 2014.

GARCÍA CANCLINI, Néstor. Políticas culturais e crise de desenvolvimento: um balanço latino-americano. In: ROCHA, Renata; BRIZUELA, Juan Ignacio (orgs.). Política cultural: conceito, trajetória e reflexões - Néstor García Canclini. Salvador: Edufba, 2019. p. 45-86.

OCHOA GAUTIER, Ana María. Entre los deseos y los derechos: un ensayo crítico sobre políticas culturales. Bogotá: INCAH, 2003.

ROCHA, Renata. Políticas culturais na América Latina: uma abordagem teórico- conceitual. Políticas Culturais em Revista, v. 9, n. 2, p. 674-703, 2016.

RUBIM, Albino. Políticas culturais entre o possível e o impossível. In: NUSSBAUMER, Gisele (org.). Teorias \& políticas de cultura. Salvador: Edufba, 2007. p. 139-158.

RUBIM, Linda Silva Oliveira; VIEIRA, Mariella Pitombo; SOUZA, Delmira Nunes de (orgs.). Enecult 10 anos. Salvador: Edufba, 2014.

SANTOS, Marcelo Augusto de Paiva dos. Políticas culturais, um campo em formação: explorações a partir de metodologias informacionais e cientométricas. (Mestrado em Antropologia e Sociologia). Universidade Federal do Rio de Janeiro, Rio de Janeiro, 2017.

SANTOS, Marcelo Augusto de Paiva. Políticas culturais, um campo em formação: explorações sociológicas a partir de metodologias informacionais e cientométricas. In: CALABRE, Lia; DOMINGUES, Alexandre (orgs.). Estudos sobre políticas culturais e gestão da cultura. Rio de Janeiro: Fundação Casa de Rui Barbosa, 2019. p. 51-74.

SOARES, Patrícia Bourguignon et al. Análise bibliométrica da produção científica brasileira sobre Tecnologia de Construção e Edificações na base de dados Web of Science. Ambiente Construído, Porto Alegre, v. 16, n. 1, p. 175-185, jan./mar. 2016.

VIEIRA, Mariella Pitombo et al. O perfil dos estudos sobre políticas culturais a partir do ENECULT. In: ENCONTRO DE ESTUDOS MULTIDISCIPLINARES EM CULTURA, 16., 2016, Salvador. Anais... Salvador: UFBA, 2016. 